\title{
One Year Later: What Was the Impact of the COVID-19 Pandemic on Orthopedic Practice?
}

Elias Vasiliadis ${ }^{1}$, Christos Vlachos ${ }^{1}$, Eftychios Papagrigorakis ${ }^{2}$, Dimitrios Stergios Evangelopoulos ${ }^{2}$, Moyssis Lelekis ${ }^{3}$, Spyros G. Pneumaticos ${ }^{1}$

1. 3rd Orthopedic Department, University of Athens, KAT General Hospital of Athens, Athens, GRC 2. 3rd Orthopedic Department, School of Medicine, National and Kapodistrian University of Athens, KAT General Hospital of Athens, Athens, GRC 3. 3rd Orthopedics Department, School of Medicine, National and Kapodistrian University of Athens, KAT General Hospital of Athens, Athens, GRC

Corresponding author: Christos Vlachos, christosorto@gmail.com

\begin{abstract}
The coronavirus disease 2019 (COVID-19) pandemic is an enormous challenge for health care systems worldwide.
\end{abstract}

Although it is widely accepted that orthopedic service has been reduced during the COVID-19 pandemic, little is known about the magnitude and qualitative characteristics of this reduction. The aim of the present study is to quantify the impact of the COVID-19 pandemic on everyday orthopedic practice and to detect the qualitative details of this impact in order to provide data for appropriate planning of health care policy.

Data from the year 2020, when the COVID-19 pandemic occurred, regarding the number of patients examined in the emergency department, outpatient clinics, as well as the number of hospital admissions, were recorded for each month. The number of surgical procedures per month was also recorded and evaluated in relation to the category and the anatomical region that these procedures pertained to. Similar data from the year 2019 were used as a control group.

The mean number of patients who visited the emergency department, the outpatient clinics, and those who were admitted to the hospital per month decreased by $47.2 \%, 30.4 \%$, and $9 \%$, respectively. Overall, the mean number of orthopedic operations decreased by $11.7 \%$, with trauma operations being reduced by $8.9 \%$ and elective operations by $13 \%$ per month.

Based on the findings of the present study, the impact of the COVID-19 pandemic on orthopedic patients is definitely negative. The establishment of new guidelines and re-distribution of resources is required to return to a normal function of orthopedic practice within hospitals.

Review began 04/25/2021 Review ended 04/27/2021 Published 06/29/2021

\section{() Copyright 2021}

Vasiliadis et al. This is an open access article distributed under the terms of the Creative Commons Attribution License CC-BY 4.0., which permits unrestricted use, distribution, and reproduction in any medium, provided the original author and source are credited.
Categories: Orthopedics, Epidemiology/Public Health, Trauma

Keywords: orthopedic, covid-19, pandemic, trauma, elective, surgeries

\section{Introduction}

The coronavirus disease 2019 (COVID-19) pandemic is an enormous challenge for health care systems worldwide. Medical practice has shifted toward the treatment of patients with the COVID-19 disease. Both human and economic resources are redistributed for the creation of additional facilities to meet the increased requirements of those patients.

Orthopedic practice has definitely been affected both for its elective and emergency service [1]. Patients with chronic musculoskeletal disorders are advised to postpone definitive treatment if possible and access to outpatient clinics is restricted following guidelines issued by medical authorities. On the other hand, emergency orthopedic service remains unaltered, and all trauma patients receive appropriate treatment as they did before the pandemic. Although it is widely accepted that orthopedic service has been reduced during the COVID-19 pandemic, little is known about the magnitude and qualitative characteristics of this reduction.

The first COVID-19 patient in Greece was diagnosed on February 26, 2020, and since then the pandemic has spread across the whole country. Health authorities issued restrictions for most social activities since then, and from March 23, 2020, a strict lockdown was applied in the whole country for six weeks. A gradual restart of social activities was allowed by the end of June 2020 although recommendations regarding social distancing and mask-wearing remained. Following a second wave of the pandemic, a new lockdown was ordered commencing November 9, 2020, until the end of the year. During the first lockdown, all hospital admissions were suspended except trauma and emergency patients. Outpatient clinics were canceled and elective operations were postponed. During the second lockdown, government directives were to diminish elective procedures and outpatient clinic attendances by $80 \%$ to overload the health care system and to 
preserve stuff and equipment for COVID-19 patients [2].

The aim of the present study is to quantify the impact of the COVID-19 pandemic in everyday orthopedic practice and to detect the qualitative details of this impact in order to provide data for appropriate planning of health care policy.

\section{Materials And Methods}

The study was performed in an academic orthopedic department within a public hospital in Greece, which is a tertiary referral center for both elective and emergency practice. After ethical approval by the Institutional Review Board of KAT Hospital, medical records of all patients who were admitted in our department in 2019 and 2020 were retrospectively analyzed. Patient hospitalization, outpatient clinics, and emergency department visits, elective and trauma operations for each month of the above two-year period were recorded.

Our department is in a non-COVID-19 hospital, although there is an intensive care unit dedicated to treating COVID-19 patients. During the first six months of the pandemic, every new admission was screened for COVID-19 symptoms, and a thorough travel and contact history was recorded. For patients at risk, a reverse transcription-polymerase chain reaction (RT-PCR) test for severe acute respiratory syndrome coronavirus 2 (SARS-COV-2) was carried out. Since July 1, 2020, a negative RT-PCR test was required from all patients prior to admission to the hospital.

For each month of 2019 and 2020, differences in the number of patients examined in the emergency department and the outpatient clinics, as well as the number of patients admitted to our department for further evaluation, were recorded. The number of surgical procedures was also recorded and evaluated in relation to the category (emergency or elective) and the anatomical location that these procedures were performed.

Data from the year 2019 were used as a control group since the operation of our department had not yet been affected by the COVID-19 pandemic. Differences between each month of 2019 and 2020 were documented. Data were analyzed separately for each month because the impact of the COVID-19 pandemic was not equally distributed, as different restrictions and guidelines were in use throughout the year 2020 .

Statistical analysis was performed using the IBM Statistical Package for the Social Sciences (SPSS) v. 22.0 for Windows (IBM Corp, Armonk, NY). Descriptives of all the examined variables are provided for each month of the examined years. Continuous cohort variables were compared using the Mann-Whitney U test with Bonferroni correction to adjust for multiple comparisons. P-value $<.05$ was considered statistically significant.

\section{Results}

A mean decrease of $47,2 \%$ in the mean value was recorded when comparing the number of patients examined in the emergency department during the pre-pandemic year 2019 and the pandemic year 2020. The number of visits dropped from $1042.3 \pm 160.3$ per month in 2019 , to $550.3 \pm 239.2$ per month in 2020 (p<0.001) (Table 1).

\begin{tabular}{|c|c|c|c|c|c|c|}
\hline & \multicolumn{2}{|l|}{2019} & \multicolumn{2}{|l|}{2020} & \multirow[b]{2}{*}{ Change } & \multirow[b]{2}{*}{ p-value } \\
\hline & Mean \pm SD & Median (IQR) & Mean \pm SD & Median (IQR) & & \\
\hline Emergency Department & $1042.33 \pm 160.310$ & $1038.0(716-1365)$ & $550.33 \pm 239.241$ & $474(246-996)$ & $-47.20 \%$ & $<0.001$ \\
\hline Admissions & $186.58 \pm 21.878$ & $191.50(146-211)$ & $169.83 \pm 41.264$ & $173(89-223)$ & $-8.98 \%$ & 0.436 \\
\hline Outpatient Clinics & $509 \pm 70.253$ & $517(340-602)$ & $354.17 \pm 97.855$ & $360(166-473)$ & $-30.42 \%$ & $<0.001$ \\
\hline Total Number of Operations & $88.42 \pm 10.808$ & $91(64-105)$ & $78.08 \pm 14.094$ & $80(47-104)$ & $-11.69 \%$ & 0.035 \\
\hline Trauma Operations & $58.17 \pm 6.206$ & $58(46-68)$ & $53 \pm 11.481$ & $48.50(41-77)$ & $-8.88 \%$ & 0.088 \\
\hline Elective Operations & $28.92 \pm 8.295$ & $29.50(8-40)$ & $25.17 \pm 12.164$ & $26.50(1-40)$ & $-12.97 \%$ & 0.470 \\
\hline
\end{tabular}

TABLE 1: Changes in the total number of patients examined in the emergency department and outpatient clinics, the admissions, and the number of trauma and elective operations performed in the years 2019 (before the COVID-19 pandemic) and 2020 (during the COVID-19 pandemic) 


\section{Cureus}

This drop was noted during the whole year of 2020, except January, when the COVID-19 pandemic was not present, and June, when restriction measures had been withdrawn (Table 2; Figure 1).

\begin{tabular}{llll}
\hline Emergency Department & & & \\
Month & 2019 & 2020 & Change \\
Jan & 716 & 768 & $7.3 \%$ \\
Feb & 1365 & 872 & $-36.1 \%$ \\
Mar & 1049 & 581 & $-44.6 \%$ \\
Apr & 974 & 399 & $-59.0 \%$ \\
May & 1126 & 715 & $-36.5 \%$ \\
Jun & 1006 & 996 & $-1.0 \%$ \\
Jul & 1027 & 400 & $-61.1 \%$ \\
Aug & 957 & 267 & $-72.1 \%$ \\
Sep & 1158 & 436 & $-62.3 \%$ \\
Oct & 1117 & 512 & $-54.2 \%$ \\
Nov & 884 & 412 & $-53.4 \%$ \\
Dec & 1129 & 246 & $-78.2 \%$
\end{tabular}

TABLE 2: Number of patients examined per month of 2019 and 2020 in the emergency department, and their change in percentage

Emergency Department visits

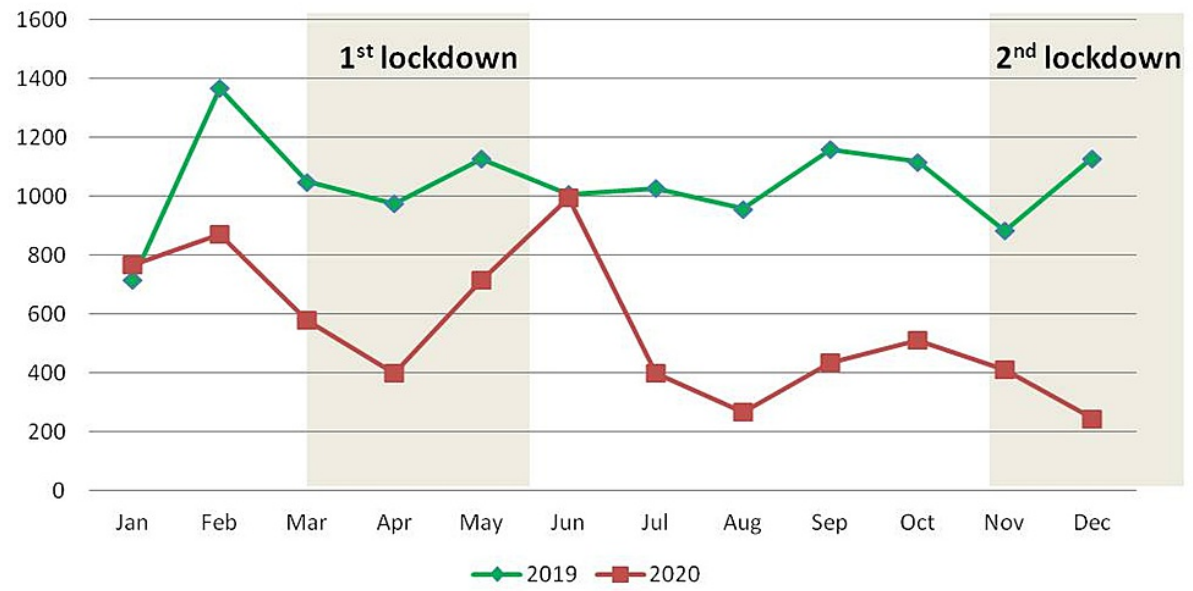

FIGURE 1: Monthly distribution of the number of patients who visited the emergency department

The mean value of the total number of visits in the outpatient clinics fell by $30.4 \%$, from $509 \pm 70.3$ per month in 2019 to $354.2 \pm 97.86$ per month in $2020(p<0.001)$ (Table 3). This reduction was documented during the entire 2020 but was more prominent during March, April, and May, when the first lockdown had been issued (Table 3; Figure 2). 


\section{Cureus}

$\begin{array}{llll}\text { Outpatient Clinics } & & & \\ \text { Month } & 2019 & 2020 & \text { Change } \\ \text { Jan } & 602 & 473 & -21.4 \% \\ \text { Feb } & 507 & 445 & -12.2 \% \\ \text { Mar } & 512 & 221 & -56.8 \% \\ \text { Apr } & 485 & 166 & -65.8 \% \\ \text { May } & 541 & 307 & -43.6 \% \\ \text { Jun } & 522 & 341 & -34.7 \% \\ \text { Jul } & 545 & 407 & -25.3 \% \\ \text { Aug } & 340 & 273 & -19.7 \% \\ \text { Sep } & 600 & 364 & -39.3 \% \\ \text { Oct } & 523 & 440 & -15.9 \% \\ \text { Nov } & 495 & 457 & -7.7 \% \\ \text { Dec } & 436 & 356 & -18.3 \%\end{array}$

TABLE 3: Number of patients examined per month of 2019 and 2020 in the outpatient clinics and their change in percentage

\section{Outpatient Clinics visits}

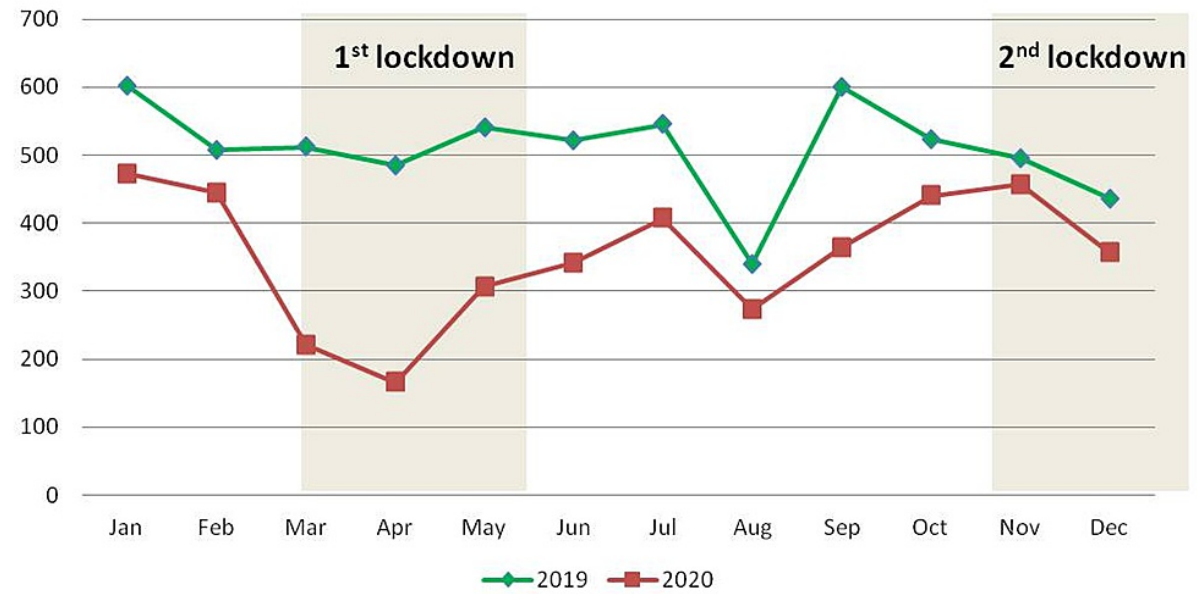

FIGURE 2: Monthly distribution of the number of patients examined at the outpatient clinics

The mean value of hospital admissions decreased by $9 \%$ from $186.6 \pm 21.9$ per month in 2019 to $169.8 \pm 41.3$ per month in 2020. This difference was not statistically significant (Table 1). When studying hospital admissions by month, it was found that a noticeable reduction was present during March (20.5\%), April (50.8\%), and May (41.4\%) of 2020 as well as December (31.7\%) of 2020 when the first and second lockdown had been ordered respectively (Table 4; Figure 3). 


\section{Cureus}

\begin{tabular}{llll}
\hline Admissions & 2019 & 2020 & Change \\
Month & 149 & 170 & $14.1 \%$ \\
Jan & 182 & 186 & $2.2 \%$ \\
Feb & 190 & 151 & $-20.5 \%$ \\
Mar & 181 & 89 & $-50.8 \%$ \\
Apr & 210 & 123 & $-41.4 \%$ \\
May & 196 & 211 & $7.7 \%$ \\
Jun & 172 & 223 & $29.7 \%$ \\
Jul & 146 & 150 & $2.7 \%$ \\
Aug & 207 & 203 & $-1.9 \%$ \\
Sep & 211 & 218 & $3.3 \%$ \\
Oct & 193 & 176 & $-8.8 \%$ \\
Nov & 202 & 138 & $-31.7 \%$ \\
Dec & & &
\end{tabular}

TABLE 4: Numbers of hospital admissions per month of 2019 and 2020 and their change in percentage

\section{Admissions}

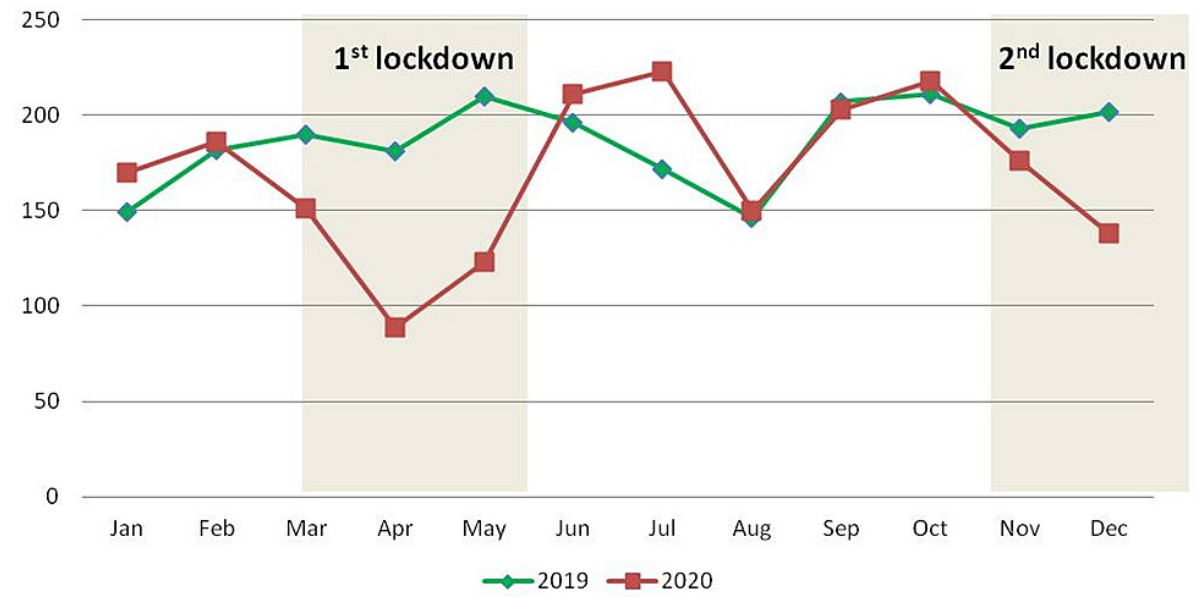

FIGURE 3: Monthly distribution of the number of patients admitted to the hospital

The mean value of overall orthopedic operations (elective as well as trauma) performed in our department decreased by $11.7 \%$ from $88.4 \pm 10.8$ per month of 2019 to $78.1 \pm 14.1$ per month of 2020 ( $\mathrm{p}=0.035)$. This reduction was evident throughout 2020, except for January and August, when an increase of 20.3\% was recorded (Table 5; Figure 4). 


\section{Cureus}

Number of operations

$\begin{array}{llll}\text { Month } & 2019 & 2020 & \text { Change } \\ \text { Jan } & 76 & 84 & 10.5 \% \\ \text { Feb } & 95 & 82 & -13.7 \% \\ \text { Mar } & 86 & 83 & -3.5 \% \\ \text { Apr } & 81 & 47 & -42.0 \% \\ \text { May } & 87 & 70 & -19.5 \% \\ \text { Jun } & 89 & 104 & 16.9 \% \\ \text { Jul } & 93 & 86 & -7.5 \% \\ \text { Aug } & 64 & 77 & 20.3 \% \\ \text { Sep } & 95 & 78 & -17.9 \% \\ \text { Oct } & 105 & 89 & -15.2 \% \\ \text { Nov } & 96 & 64 & -24.0 \% \\ \text { Dec } & 94 & 73 & -31.9 \%\end{array}$

TABLE 5: Total number of orthopedic operations per month of 2019 and 2020 and their change in percentage

\section{Total number of Operations}

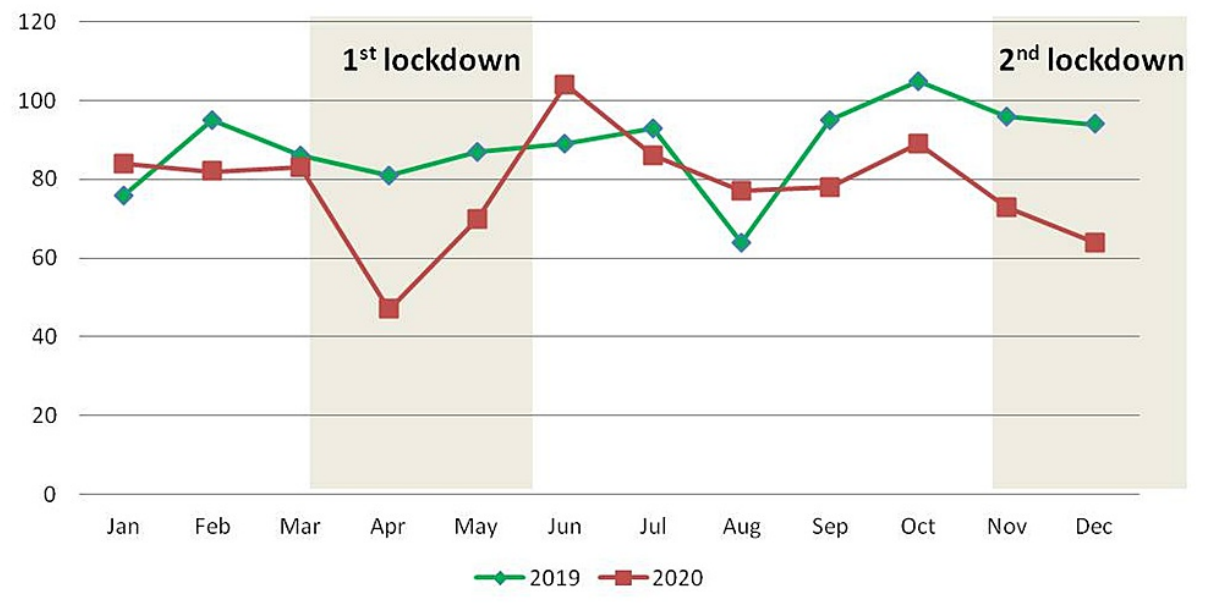

FIGURE 4: Monthly distribution of the total number of orthopedic operations

The mean value of trauma operations fell by $8.9 \%$ from $58.2 \pm 6.2$ per month of 2019 to $53 \pm 11.5$ per month of 2020 while elective operations fell by $13 \%$ from $28.9 \pm 8.3$ per month of 2019 to $25.2 \pm 12.2$ per month of 2020. The reduction in both trauma and elective operations was not statistically significant (Table 1). The difference in the number of operations was not equally distributed throughout 2020 and a considerable variation was manifested between months (Table 6; Figure 5). 


\section{Cureus}

Trauma Operations

$\begin{array}{llll}\text { Month } & 2019 & 2020 & \text { Change } \\ \text { Jan } & 46 & 48 & 4.3 \% \\ \text { Feb } & 64 & 42 & -34.4 \% \\ \text { Mar } & 59 & 66 & 11.9 \% \\ \text { Apr } & 56 & 46 & -17.9 \% \\ \text { May } & 57 & 51 & -10.5 \% \\ \text { Jun } & 50 & 77 & 54.0 \% \\ \text { Jul } & 68 & 49 & -27.9 \% \\ \text { Aug } & 56 & 69 & 23.2 \% \\ \text { Sep } & 59 & 45 & -23.7 \% \\ \text { Oct } & 62 & 54 & -12.9 \% \\ \text { Nov } & 56 & 48 & -14.3 \% \\ \text { Dec } & 65 & 41 & -36.9 \%\end{array}$

Elective Operations

20192020

Change

$20.0 \%$

$29.0 \%$

$-37.0 \%$

$-96.0 \%$

$-36.7 \%$

$-30.8 \%$

$48.0 \%$

$0 \%$

$-8.3 \%$

$29.6 \%$

$-35.0 \%$

$-20.7 \%$

TABLE 6: Numbers of trauma and elective operations per month of 2019 and 2020 and their change in percentage

Trauma Operations

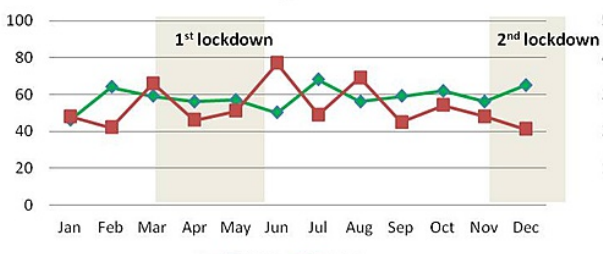

$\rightarrow 2019 \rightarrow-2020$
Elective Operations

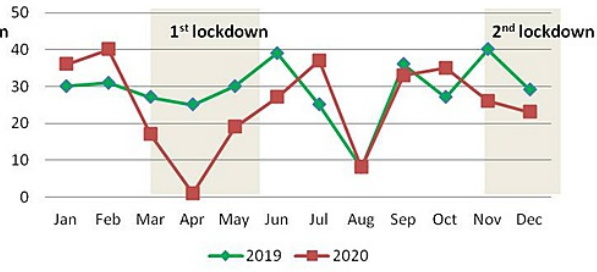

$\rightarrow 2019 \rightarrow-2020$

FIGURE 5: Monthly distribution of the number of trauma and elective operations

Analysis of trauma operations revealed a reduction in hip procedures by $19.6 \%$ from $25.5 \pm 7.2$ per month of 2019 to $20.5 \pm 4.0$ per month of 2020 . Lower limb procedures were reduced by $2.6 \%$ from $15.8 \pm 2.6$ per month of 2019 to $15.4 \pm 4.6$ per month of 2020 . Spinal procedures were reduced by $34.8 \%$ from $1.9 \pm 1.4$ per month of 2019 to $1.3 \pm 1.3$ per month of 2020 and infections were reduced by $2.9 \%$ from $8.6 \pm 3.4$ per month of 2019 to $8.3 \pm 4.8$ per month of 2020 . Upper limb procedures showed an increase of $24.6 \%$ from $5.4 \pm 2.9$ per month of 2019 to $6.8 \pm 3.4$ per month of 2020 . None of the above changes was statistically significant after Bonferroni correction for multiple testing. Details and absolute numbers are shown in Table 7. 


\begin{tabular}{|l|lllll|l|}
\hline & 2019 & & 2020 & & \\
& Mean \pm SD & Median (IQR) & Mean \pm SD & Median (IQR) & Change & $p$ value \\
\hline Trauma Hip Operations & $25.5 \pm 7.154$ & $26(15-39)$ & $20.5 \pm 3.966$ & $22.5(11-25)$ & $-19.61 \%$ & 0.059 \\
Trauma Lower Limb Operations & $15.83 \pm 2.552$ & $16(11-20)$ & $15.42 \pm 4.582$ & $13.5(10-24)$ & $-2.63 \%$ & 0.451 \\
Trauma Upper Limb Operations & $5.42 \pm 2.948$ & $5.5(1-11)$ & $6.75 \pm 3.441$ & $7(2-15)$ & $+24.62 \%$ & 0.307 \\
Trauma Spinal Operations & $1.92 \pm 1.442$ & $2(0-4)$ & $1.25 \pm 1.288$ & $1(0-4)$ & $-34.78 \%$ & 0.236 \\
Infections & $8.58 \pm 3.370$ & $8.5(2-15)$ & $8.33 \pm 4.774$ & $8(1-20)$ & $-2.9 \%$ & 0.706 \\
Total Hip Arthroplasty & $8.08 \pm 4.188$ & $8(2-17)$ & $6.33 \pm 4.271$ & $7.5(0-12)$ & $-21.65 \%$ & 0.562 \\
Total Knee Arthroplasty & $3.83 \pm 1.801$ & $4(2-8)$ & $3.08 \pm 2.353$ & $3.5(0-6)$ & $-19.57 \%$ & 0.493 \\
Elective Shoulder Operations & $1.25 \pm 0.662$ & $1(0-2)$ & $1.33 \pm 1.371$ & $1(0-4)$ & $+6.67 \%$ & 0.713 \\
Elective Spinal Operations & $6.42 \pm 2.968$ & $6(0-12)$ & $4.42 \pm 2.193$ & $5(0-8)$ & $-31.17 \%$ & 0.048 \\
Deformities & $4 \pm 2.558$ & $3.5(1-8)$ & $3.92 \pm 2.999$ & $3(1-10)$ & $-2.08 \%$ & 0.861 \\
Knee Arthroscopy & $6.67 \pm 3.143$ & $6(3-12)$ & $6.08 \pm 4.337$ & $5.5(0-14)$ & $-8.75 \%$ & 0.542 \\
\hline
\end{tabular}

TABLE 7: Changes in the number of trauma and elective operations performed in the years 2019 (before the COVID-19 pandemic) and 2020 (during the COVID-19 pandemic)

Details for the different categories of trauma operations and their monthly distribution for the years 2019 and 2020, respectively, are shown in Table 8 and Figure 6.

\begin{tabular}{|c|c|c|c|c|c|c|c|c|c|c|c|c|c|c|c|}
\hline \multirow[b]{2}{*}{ Month } & \multicolumn{3}{|c|}{ Hip Operations } & \multicolumn{3}{|c|}{ Lower Limb Operations } & \multicolumn{3}{|c|}{ Upper Limb Operations } & \multicolumn{3}{|c|}{ Spinal Operations } & \multicolumn{3}{|c|}{ Infections } \\
\hline & 2019 & 2020 & $\%$ & 2019 & 2020 & $\%$ & 2019 & 2020 & $\%$ & 2019 & 2020 & $\%$ & 2019 & 2020 & $\%$ \\
\hline Jan & 17 & 23 & $35.3 \%$ & 12 & 11 & $-8.3 \%$ & 5 & 8 & $60.0 \%$ & 3 & 1 & $-66.7 \%$ & 9 & 5 & $-44.4 \%$ \\
\hline Feb & 39 & 11 & $-71.8 \%$ & 15 & 13 & $-13.3 \%$ & 1 & 5 & $400.0 \%$ & 2 & 1 & $-50.0 \%$ & 6 & 11 & $83.3 \%$ \\
\hline Mar & 26 & 23 & $-11.5 \%$ & 16 & 24 & $50.0 \%$ & 8 & 9 & $12.5 \%$ & 2 & 0 & $-100.0 \%$ & 6 & 10 & $66.7 \%$ \\
\hline Apr & 28 & 20 & $-28.6 \%$ & 11 & 15 & $36.4 \%$ & 2 & 3 & $50.0 \%$ & 0 & 0 & $0 \%$ & 9 & 6 & $-33.3 \%$ \\
\hline May & 18 & 25 & $38.9 \%$ & 14 & 14 & $0 \%$ & 6 & 2 & $-66.7 \%$ & 4 & 3 & $-25.0 \%$ & 15 & 7 & $-53.3 \%$ \\
\hline Jun & 15 & 23 & $53.3 \%$ & 17 & 23 & $35.3 \%$ & 7 & 6 & $-14.3 \%$ & 3 & 4 & $33.3 \%$ & 8 & 20 & $150.0 \%$ \\
\hline Jul & 31 & 16 & $-48.4 \%$ & 18 & 13 & $-27.8 \%$ & 4 & 8 & $100.0 \%$ & 4 & 2 & $-50.0 \%$ & 10 & 10 & $0 \%$ \\
\hline Aug & 26 & 23 & $-11.5 \%$ & 16 & 18 & $12.5 \%$ & 4 & 15 & $275.0 \%$ & 2 & 1 & $-50.0 \%$ & 8 & 11 & $37.5 \%$ \\
\hline Sep & 32 & 23 & $-28.1 \%$ & 16 & 10 & $-37.5 \%$ & 2 & 5 & $150.0 \%$ & 0 & 0 & $0 \%$ & 7 & 5 & $-28.6 \%$ \\
\hline Oct & 19 & 19 & $0 \%$ & 20 & 19 & $-5.0 \%$ & 8 & 8 & $0 \%$ & 2 & 2 & $0 \%$ & 13 & 5 & $-61.5 \%$ \\
\hline Nov & 25 & 18 & $-28.0 \%$ & 18 & 12 & $-33.3 \%$ & 11 & 8 & $-27.3 \%$ & 0 & 0 & $0 \%$ & 2 & 9 & $350.0 \%$ \\
\hline Dec & 30 & 22 & $-26.7 \%$ & 17 & 13 & $-23.5 \%$ & 7 & 4 & $-42.9 \%$ & 1 & 1 & $0 \%$ & 10 & 1 & $-90.0 \%$ \\
\hline
\end{tabular}

TABLE 8: Monthly distribution of different categories of trauma operations in the years 2019 (before the COVID-19 pandemic) and 2020 (during the COVID-19 pandemic) 


\section{Cureus}

Hip Operations (Trauma)

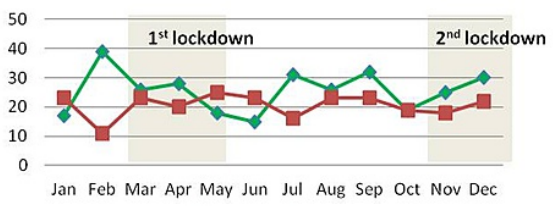

$\rightarrow 2019-2020$

Upper Limb Operations

(Trauma)

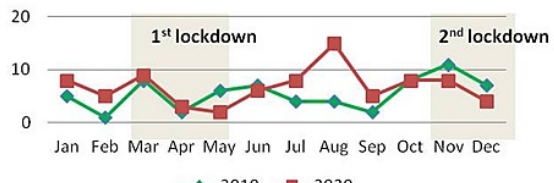

Operations for Infections

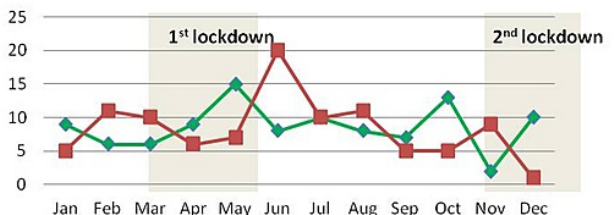

$\rightarrow 2019 \rightarrow-2020$
Lower Limb Operations

(Trauma)

$1^{\text {st lockdown }}$

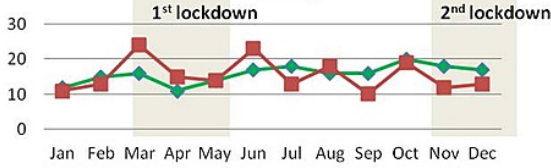

$\rightarrow 2019 \rightarrow-2020$

Spinal Operations (Trauma)

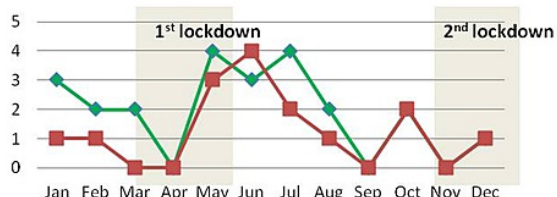

$\neg 2019 \rightarrow-2020$

FIGURE 6: Monthly distribution of the number of trauma operations by category

Analysis of elective operations showed a decrease of total hip arthroplasties by $21.7 \%$ from $8.1 \pm 4.2$ per month of 2019 to $6.3 \pm 4.3$ per month of 2020 . Total knee arthroplasties were decreased by $19.6 \%$ from $3.8 \pm$ 1.8 per month of 2019 to $3.1 \pm 2.4$ per month of 2020 . Spinal operations were decreased by $31.2 \%$ from $6.4 \pm$ 3.0 per month of 2019 to $4.4 \pm 2.2$ per month of 2020 . Knee arthroscopies were decreased by $8.8 \%$ from $6.7 \pm$ 3.143 per month of 2019 to $6.1 \pm 4.3$ per month of 2020 and deformity corrections were decreased by $2.1 \%$ from $4 \pm 2.6$ per month of 2019 to $3.9 \pm 3.0$ per month of 2020 . Shoulder operations were increased by $6.7 \%$ from $1.3 \pm 0.7$ per month of 2019 to $1.3 \pm 1.4$ per month of 2020. After Bonferroni correction for multiple testing, all changes, except for the reduction of elective spinal operations, were not statistically significant (Table 7). Monthly distribution and absolute numbers of different categories of elective operations are shown in detail in Table 9 and Figure 7. 


\section{Cureus}

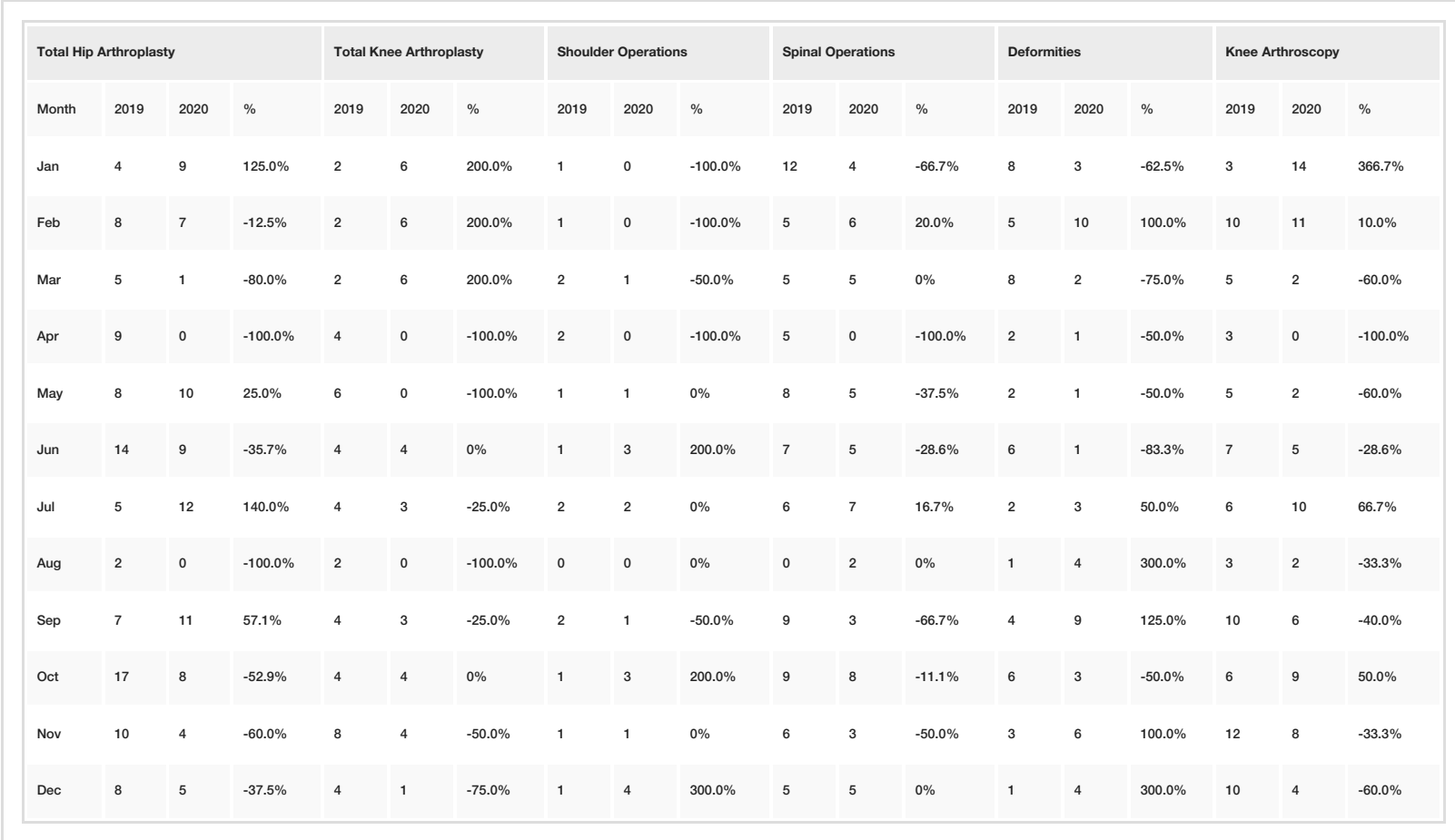

TABLE 9: Monthly distribution of different categories of elective operations in the years 2019 (before the COVID-19 pandemic) and 2020 (during the COVID-19 pandemic)
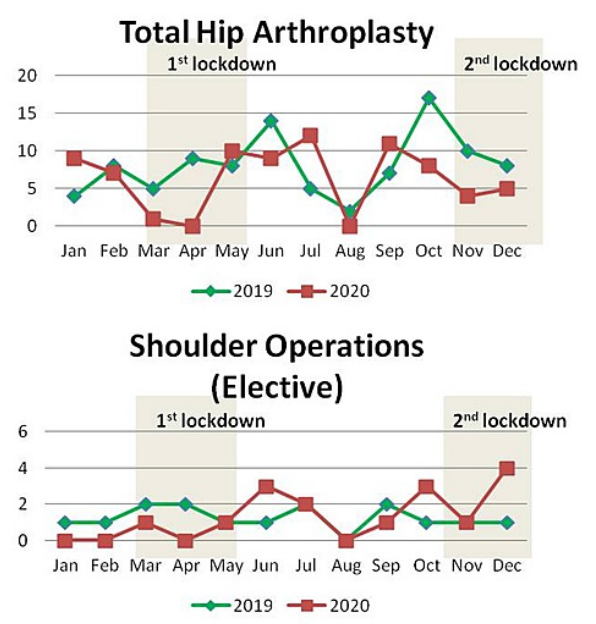

Spinal operations (Elective)

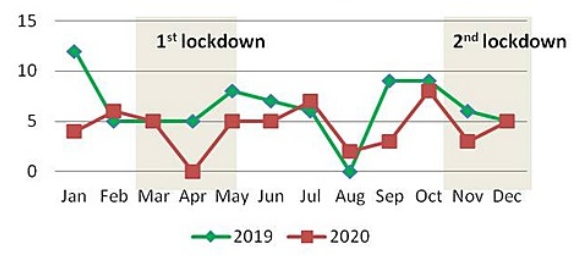

FIGURE 7: Monthly distribution of the number of elective operations by category

\section{Discussion}

The government, in an effort to control the COVID-19 pandemic, imitated other countries' measures and adopted a strict lockdown during the two peaks of the COVID-19 pandemic, with a small quarantine-free
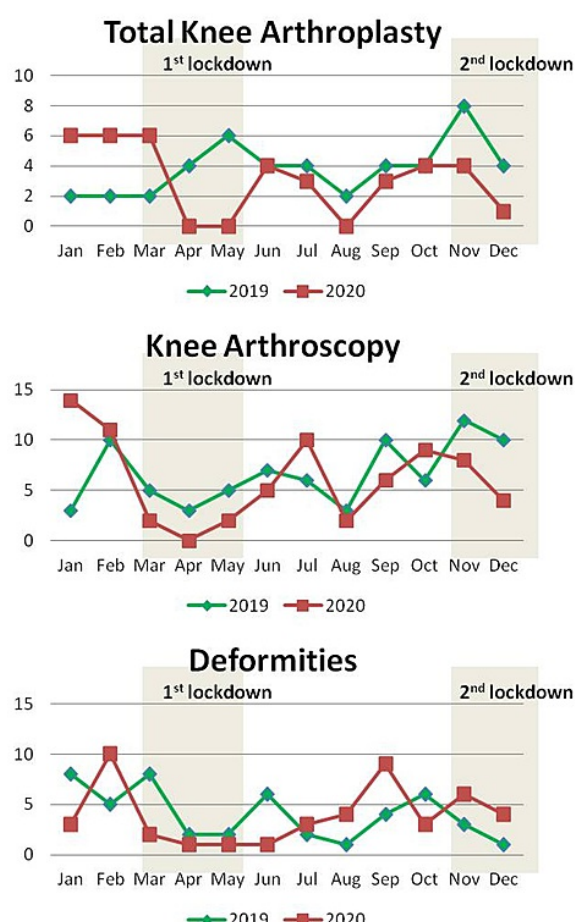

$\rightarrow 2019-2020$ 
period during summer months. People were instructed to stay home in order to stay safe, transportation between districts was prohibited, remote working was established, schools and universities suspended their operation, retail and leisure places were closed, and social distancing and mask-wearing became compulsory in an effort to eliminate the transmission of the virus among the population. As a consequence, people limited their activities and restrained visits to medical centers for chronic conditions mainly because they fear COVID-19 contamination. A notable decrease in patient numbers seeking medical consultation was monitored in hospitals, including orthopedic patients [1,3].

Initially, a significant decrease was reported in the number of patients who visited the emergency department in 2020 as compared to 2019. This is attributed to the restriction of most outdoor activities, leading to less traffic, occupational accidents, and sports injuries. Additionally, many patients with minor injuries did not ask for medical support, due to the fear of coming in contact with the COVID-19 virus or even due to altruistic motivation for health care workers [4].

Similarly, a significant reduction was found in the number of patients examined in the outpatient clinics of our department throughout the whole year of 2020. This reduction was in accordance with the hospital's administrative policy, which reduced the available appointments and increased the waiting time between patients in order to avoid overcrowding and protect health care workers from virus contamination [5-6].

On the contrary, hospital admissions significantly decreased during the first lockdown in March, April, and May 2020, but this tendency was not so evident during the second lockdown in November and December 2020. Furthermore, a minor increase in hospital admissions was noticed during the summer months. Loosening of restrictions during summer for a quarantine-free tourist period and lighter restrictions during the second lockdown are possible explanations for these findings. Consequently, these strategies led to a rise in the number of trauma patients and those looking for the treatment of chronic orthopedic disease.

Compared with the significant reduction in the visits to the emergency department, the reduction of emergency operations was disproportionally lower, mainly because the hospital is a tertiary referral center and patients who visited our department were referred for operative management rather than simple orthopedic consultation. Hip fractures presented a rather stable monthly distribution throughout 2020 and when compared to 2019, their decrease was not statistically significant, as they represent a fragility type of fracture, occur after in-house falls, and mainly affect elderly people with many co-morbidities [7]. Lower limb trauma operations did not present any significant change. Interestingly, upper limb trauma operations increased, possibly because they are related to indoor activities, which were increased during the quarantine period. Emergency spinal operations were decreased mainly because road accidents and falls from height were diminished. The number of orthopedic infections that needed surgical treatment was similar between 2019 and 2020. Periprosthetic joint infections, osteomyelitis, and septic arthritis are considered surgical emergencies and their number remained unaffected, as they represent complications of previous surgical interventions in the pre-pandemic period.

Restriction of elective operations was among the first measures that were adopted after the outbreak of the COVID-19 pandemic. Health authorities postponed the majority of elective surgeries during the first lockdown and reduced their number by $80 \%$ during the second lockdown in an effort to preserve recourses and equipment for the treatment of COVID-19 patients [8]. Despite this policy, the reduction of elective operations during 2020 in our department was less marked. Apart from elective spinal operations, which presented a statistically significant decrease, the number of joint reconstruction procedures, knee arthroscopy, shoulder elective operations, and deformity corrections showed a lower decrease and followed a biphasic monthly distribution with a significant reduction during the lockdown months and a counterbalance during the rest of 2020 as compared to 2019. One possible explanation is that many elective orthopedic operations are considered as "urgent-elective" due to the severe disability they imply for the patient and are therefore prioritized as soon as restrictive measures are alleviated [9-10].

It is still unclear whether elective surgeries will return to their normal flow; however, it is certain that once this happens, the health care system will be confronted with a huge backlog of elective surgeries [11].

\section{Conclusions}

Based on the findings of the present study, the impact of the COVID-19 pandemic on orthopedic practice is definitely negative. The access of patients with orthopedic problems is restricted and elective operations are postponed following restrictions issued by policy-makers. It is not clear what the consequences of the currently applied policy will be in the long term. It is crucial to re-establish the guidelines in order to reschedule the elective operations. There is no doubt that precautions for virus spread must be enforced and supplementary resources should be re-distributed in order to return to the normal function of orthopedic practice; otherwise, the negative impact of the COVID-19 pandemic will be sustained and many disabled patients with orthopedic diseases will lose any access to treatment.

\section{Additional Information}




\section{Disclosures}

Human subjects: Consent was obtained or waived by all participants in this study. Institutional Review Board of KAT Hospital issued approval NA. Animal subjects: All authors have confirmed that this study did not involve animal subjects or tissue. Conflicts of interest: In compliance with the ICMJE uniform disclosure form, all authors declare the following: Payment/services info: All authors have declared that no financial support was received from any organization for the submitted work. Financial relationships: All authors have declared that they have no financial relationships at present or within the previous three years with any organizations that might have an interest in the submitted work. Other relationships: All authors have declared that there are no other relationships or activities that could appear to have influenced the submitted work.

\section{References}

1. Wong JSH, Cheung KMC: Impact of COVID-19 on orthopaedic and trauma service. An epidemiological study. J Bone Joint Surg Am. 2020, 102:e80. 10.2106/JBJS.20.00775

2. Greek Government. Covid-19 Greece . (2021). http://covid19.gov.gr/covid19-live-analytics.

3. Kalantar S, Farhoud A, Mortazavi J: Lockdown of an orthopedic department during COVID-19 epidemics, our experience in a general hospital. Arch Bone Jt Surg. 2020, 8:235-41. 10.22038/abjs.2020.47834.2362

4. Turgut A, Arlı H, Altundağ Ü, Hancıoğlu S, Egeli E, Kalenderer Ö: Effect of COVID-19 pandemic on the fracture demographics: data from a tertiary care hospital in Turkey. Acta Orthop Traumatol Turc. 2020, 54:355-63. 10.5152/j.aott.2020.20209

5. Placella G, Salvato D, Delmastro E, Bettinelli G, Salini V: CoViD-19 and ortho and trauma surgery: the Italian experience. Injury. 2020, 51:1403-5. 10.1016/j.injury.2020.04.012

6. Ahmed S, Tan WLG, Chong YL: Surgical response to COVID-19 pandemic: a Singapore perspective . J Am Coll Surg. 2020, 230:1074-7. 10.1016/j.jamcollsurg.2020.04.003

7. Court-Brown CM, McQueen MM: Global forum: fractures in the elderly . J Bone Joint Surg Am. 2016, 98:e36. 10.2106/JBJS.15.00793

8. Brindle ME, Gawande A: Managing COVID-19 in surgical systems . Ann Surg. 2020, 272:e1-2. 10.1097/SLA.0000000000003923

9. DePhillipo NN, Larson CM, O'Neill OR, LaPrade RF: Guidelines for ambulatory surgery centers for the care of surgically necessary/time-sensitive orthopaedic cases during the COVID-19 pandemic. J Bone Joint Surg Am. 2020, 102:933-6. 10.2106/JBJS.20.00489

10. American College of Surgeons. COVID-19 guidelines for triage of orthopaedic patients . (2020). https://www.facs.org/covid-19/clinical-guidance/elective-case/orthopaedics.

11. Swiontkowski M: COVID-19 pandemic and JBJS. J Bone Joint Surg Am. 2020, 102:733. 10.2106/JBJS.20.00471 